\title{
Method validation and determination of caffeine in drinks in the Iranian market by the HPLC
}

\author{
Hamide Sharifi Darani ${ }^{1}$, Parisa Ziarati ${ }^{2,3}$, Mahboubeh Taherkhani ${ }^{4}, \underline{\text { Zahra Mousavi }}^{5}$ \\ ${ }^{1}$ PharmD Student, Department of Pharmacology and Toxicology, Faculty of Pharmacy and Pharmaceutical Sciences, \\ Tehran Medical Sciences, Islamic Azad University (IAUPS), Tehran, Iran \\ ${ }^{2}$ Nutrition and Food Sciences Research Center, Tehran Medical Sciences, Islamic Azad University, Tehran, Iran \\ ${ }^{3}$ Assistant Professor, Medicinal Chemistry Department, Pharmacy Faculty, Tehran Medical Sciences, Islamic Azad \\ University, Tehran, Iran \\ ${ }^{4}$ Assistant Professor, Department of Chemistry, College of Sciences, Takestan Branch, Islamic Azad University, \\ Takestan, Iran \\ ${ }_{5}^{5}$ Associate Professor, Department of Pharmacology and Toxicology, Faculty of Pharmacy and Pharmaceutical \\ Sciences, Tehran Medical Sciences, Islamic Azad University (IAUPS), Tehran, Iran
}

\begin{abstract}
Background: Caffeinated energy drinks are common drinks among athletes and general population that have benefits such as providing quick energy, reducing fatigue and creating alertness, but can lead to serious complications in patients, especially those who have cancer and mental, cardiovascular, or renal diseases. The aim of this study was to validate the quantitative analysis and determine caffeine in 10 caffeinecontaining drink samples from Tehran markets using high efficiency liquid chromatography (HPLC).

Materials and methods: In this study, first the HPLC method was validated using the sample standard. Then the amount of caffeine in 10 samples of drinks was evaluated.

Results: The calibration curve of caffeine was linear in the range of 2-200 ppm and its correlation coefficient was 0.997. The limits of detection and quantification (LOQ and LOD) were 44.65 and $13.39 \mu \mathrm{g} / \mathrm{mL}$ respectively. After validating the method, 10 drink samples collected from Tehran were tested for caffeine content. Comparing the results with international standards showed that the caffeine value of these beverages was lower than the standard.

Conclusion: This method has the accuracy and efficiency in measuring the caffeine of beverages. Comparing with international standards, the amount of caffeine in the beverages is lower than the standard. Due to the increased consumption of these drinks in the country, measuring caffeine at different times is essential.
\end{abstract}

Keywords: Caffeinated drinks, High efficiency liquid chromatography, Method validation, Caffeine value.

Cited as: Sharifi Darani H, Ziarati P, Taherkhani M, Mousavi Z. Method validation and determination of caffeine in drinks in the Iranian market by the HPLC. Medical Science Journal of Islamic Azad University, Tehran Medical Branch 2020; 30(4): 425-431.

Correspondence to: Zahra Mousavi

Tel: +989125081304

E-mail: mosavi50@yahoo.com

ORCID ID: 0000-0001-6524-491X

Received: 14 Oct 2019; Accepted: 13 Jun 2020 
مجله علوم يزشكى دانشگاه آزاد اسلامى

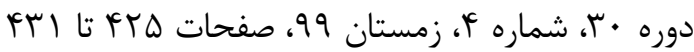

\section{اعتبار سنجى روش و اندازهيرى كافئين موجود در نوشيدنىهاى بازار ايران به وسيله كروماتوكر افى مايع با كارايى بالا}

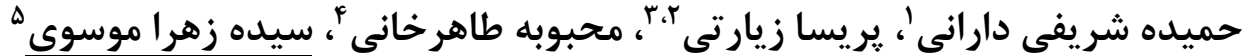

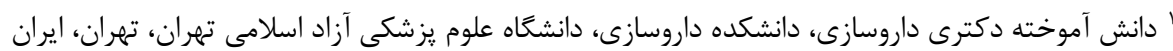

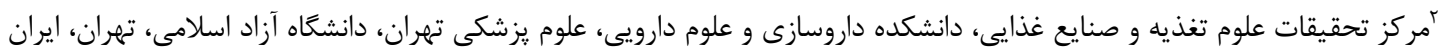

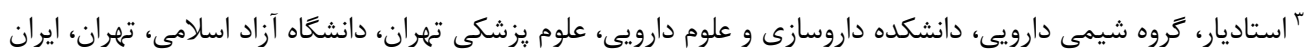

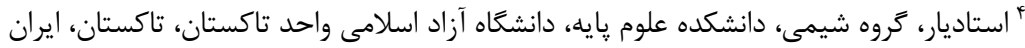

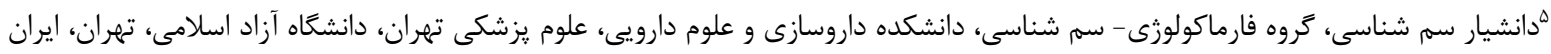
جـكبه

سابقه و هدف: نوشيدنىهاى انرزىزا و حاوى كافئين /ز جمله نوشيدنىهاى رايج توسط ورزشكاران و عموم مردم هستند كه فوايدى

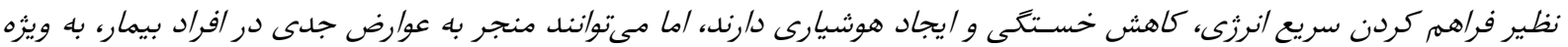

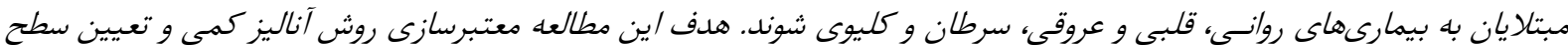

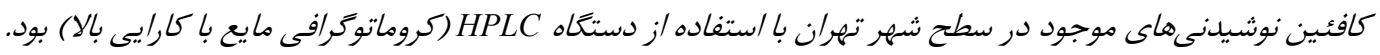

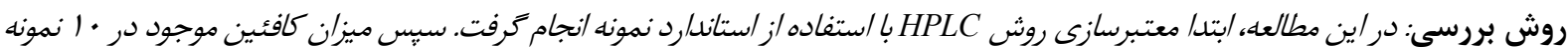
ازونسيدنىها بررسى شد.

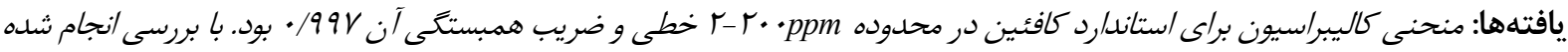

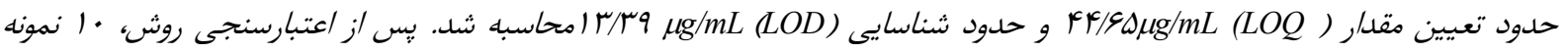

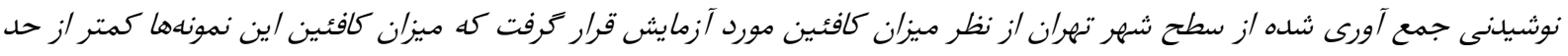
/ استاند/رد بود.

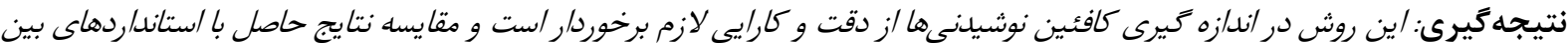

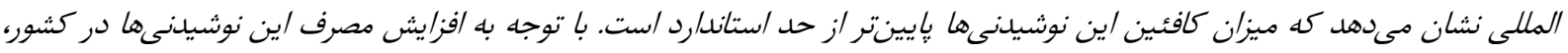

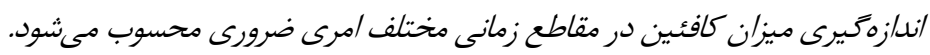

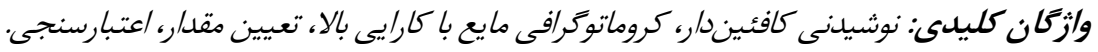

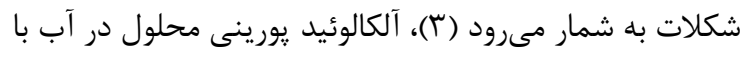

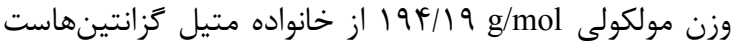

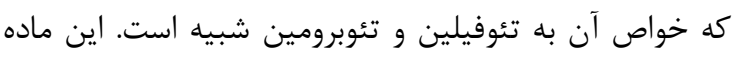

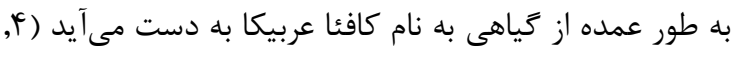

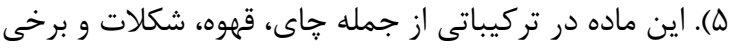

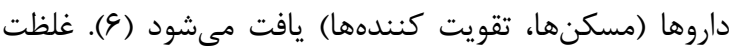

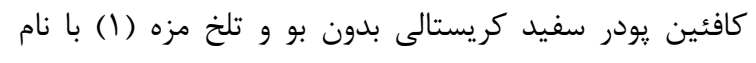

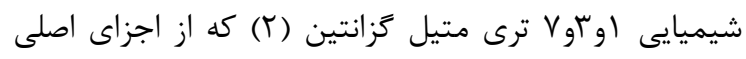

آدرس نويسنده مسئول: تهران، كروه فارماكولوزى سم شناسى، دانشكده داروسازى و علوم دارويى، سيده

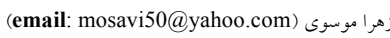
ORCID ID: 0000-0001-6524-491X تاريخ دريافت مقاله: GN/V/Tr

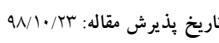


فيزيولوزيكى و تشديد اختلالات روانى مىشود. مقدار مصرف

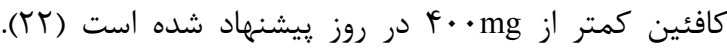
مقداركافئين در نوشيدنىهاى غيرالكلى طبق قانون سازمان غذا و دارو آمريكا (Food and Drug Administration :FDA)

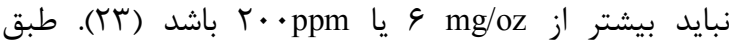
استاندارد ملى مقدار كافئين در نوشابههاى انرزىزا و كازدار نبايد به ترتيب بيشتر ازppm • r و و •ppm • • باشد. ميزان دريافت روزانه قابل قبول براى كافئين در افراد بزر آسال 

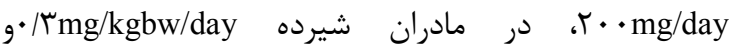

دركودكان mg/kgbw/day r ذكر شده است (TF). كروماتوكرافى مايع با كارايى بالا، روشى مناسب جهت الدهان

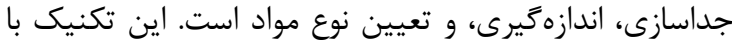
تلفيق با روشهاى ديكر و آشكارسازهاى بيشرفته كاربردهاى

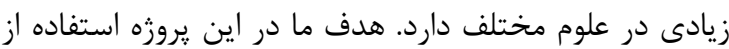

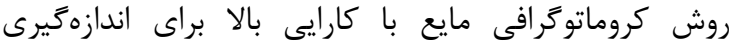
كافئين نوشيدنىهاى موجود در بازار بود.

\section{مواد و روشهها مواد و تجهيزات مورد استفاده}

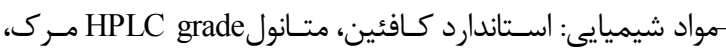

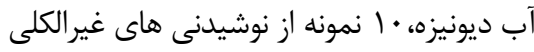

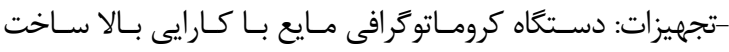

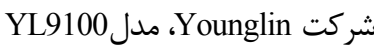
آماده سازى استاندارد

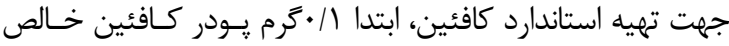

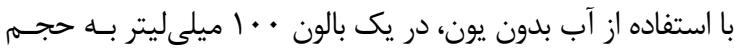

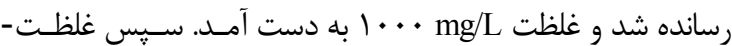

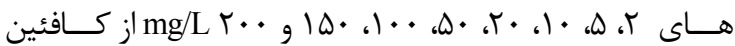

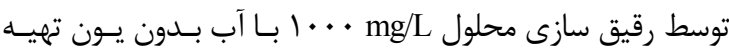

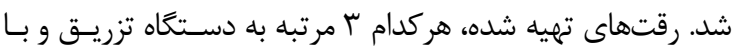
استفاده از ميانگين حاصل شده، توسـط نـــــ افـزار اكسـل نمـودار

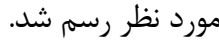

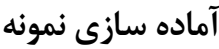

ميزان r ميلى ليتر از هر نمونه، به وسيله آب ديونيزه بـه حجـم .

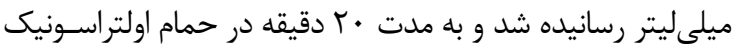

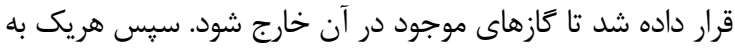

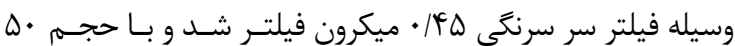

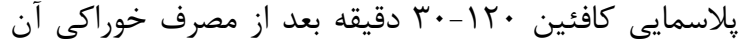

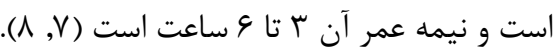

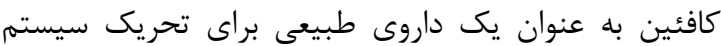
اعصاب مركزى و متابوليك عمل مى كند و از جمله اثرات آن بران مىتوان به تحريك سيستم عصبى، ديورز، ترشح اسيد معده

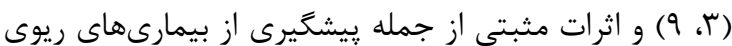

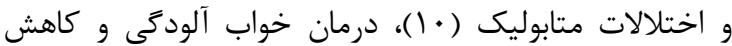
خستگى جسمانى (11) و در برخى موارد ارتباط با شناخت

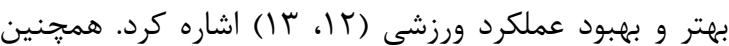
نتايج برخى تحقيقات حاكى از آن است كه مصرف تركيبات

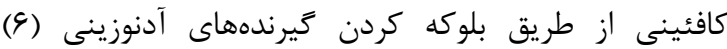
افزايش سنتز آنزيمهاى آنتى اكسايشى (V) و وكاهش تونى

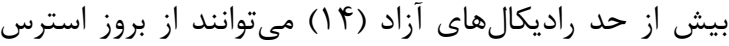

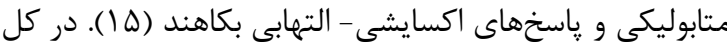
به نظر مىرسد كه كافئين اعمال ضد التهابى و محافظت كنندگى خود را از طريق مهار كيرندههاى آدنوزينى به ويزه

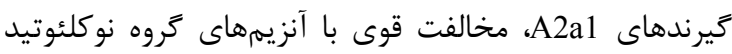
فسفودى استراز و افزايش توليد بيام آور درون سلولى آدنوزين مونو فسفات ملقوى (cAMP) Cyclic adenosine (monophosphate كه باعث فعال كردن مسير توليد يروتئين

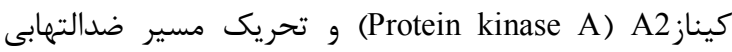
cAMP/PKA كموتاكسى، حركت، جسبندگى و فعاليت انواع سلولهاى التهابى شامل سلولهاى T كشنده، لنفوسيتها و نوتروفيلها مىشود (19). از جمله اثرات منفى كافئين مىتوان به بـى اشتهايى، افزايش

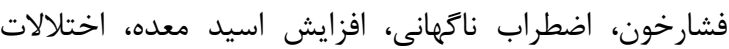

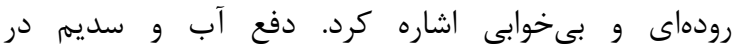
نوشيدنىهاى انرزىزا كزارش شده است كه اين عوارض به بهاري

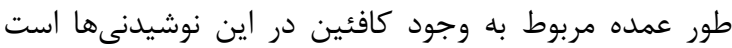

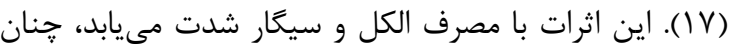
كه حمله صرعى در خصوص مصرف نوشيدنىهاى انرزىزا

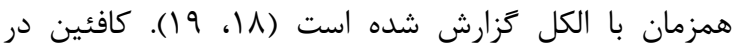
دوزهاى بالا به شدت سمى است و سبب علايم بسيارى مانند

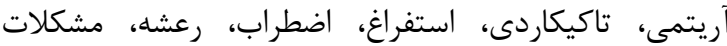

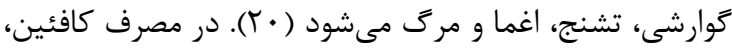
سردرد، خستگى و درد عضلانى مشاهده شده است كه اين آنس

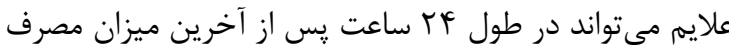

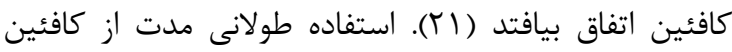

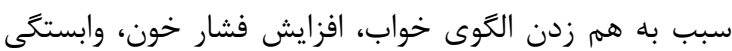


دقت: نتايج تكراريذيرى در سه روز متوالى به صورت ميانگين \pm انحراف معيار و درصد انحراف نسبى دادهها در جدول r ارائه شده است.

غلظت كافئين در نوشيدنى ها

در جدول r نتايج روش HPLC در نمونههاى مختلف نوشيدنى ها نشان داده شده است.

ميزان دريافت تخمينى روزانه

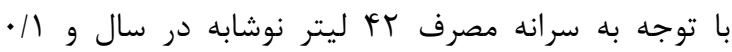

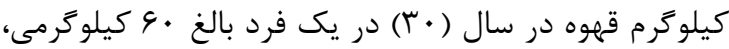
ميزان متوسط دريافت روزانه كافئين از مصرف نوشابه و قهوه مطابق با فرمول ارائه شده محاسبه و مقادير با ميزان

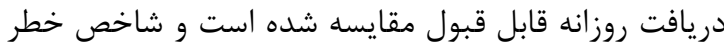
محاسبه شد. (HI)

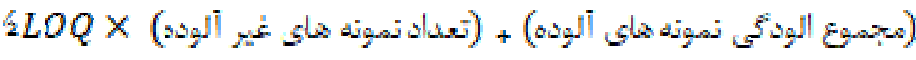

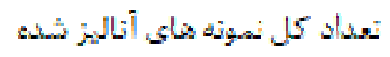

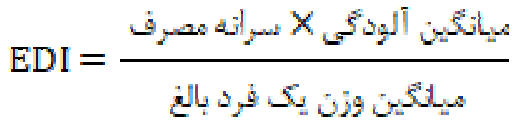

\section{بحث}

كافئين آلكالوئيدى طبيعى است و از اجزاى اصلى نوشيدنى هايى مانند قهوه و خاى و نيز شكلات و ... به شمار مىرود. متوسط مصرف كافئين در انسان در محدوده •^ تا

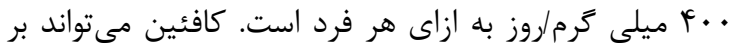
كيفيت و كميت خواب اثركذار باشد. اثرات قطع مصرف هرف كافئين در انسان، سردرد، خستخى و خواب آلودگى است.

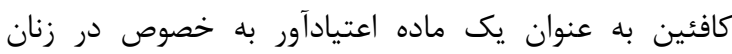

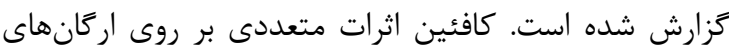
بدن از جمله سيستم عصبى، قلبى عروقى، گوارشى و تنفسى دارد و باعث تحريك سيستم اعصاب مركزى، اثرات ضدالتهابى، فراهم سازى انرزى، ييشخيرى از بيمارىهاى ريوى و اختلالات متابوليك مىشود. همجنين كافئين در دوزهاى بالا باعث اضطراب، افزايش فشار خون، بروز مشكلات قلبى عروقى و

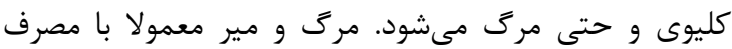

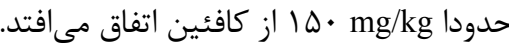

ميكروليتر به دستگاه تزريق شد. يِيك كافئين به طـور متوسـط در زمان بازگشت ه دقيقه ظاهر شد.

يافتهها

نتايج حاصل از معتبرسازى روش اجرايى به شرح زير به دست آمد. خطى بودن: ارزيابى خطى بودن و تعيين معادله خط در جدول و نمودار ا ارائه شده است. لورني

\begin{tabular}{|c|c|}
\hline مساحت زير منحنى (mV*Sec) & غلظت كافئين (mg/L) \\
\hline$V M / V G$ & r \\
\hline $1 r q / \Delta 1$ & $\Delta$ \\
\hline$T F \cdot \mid g T$ & $1 \cdot$ \\
\hline FTr/At & $r \cdot$ \\
\hline $1.9 r / 4 r$ & $\Delta \cdot$ \\
\hline THEI/VR & $1 \cdots$ \\
\hline THMN/DF & 10 . \\
\hline F^১৭/V r & $r \cdot$. \\
\hline
\end{tabular}

جدول ا. مساحت زير منحنى استاندارد كافئين در غلظتهاى

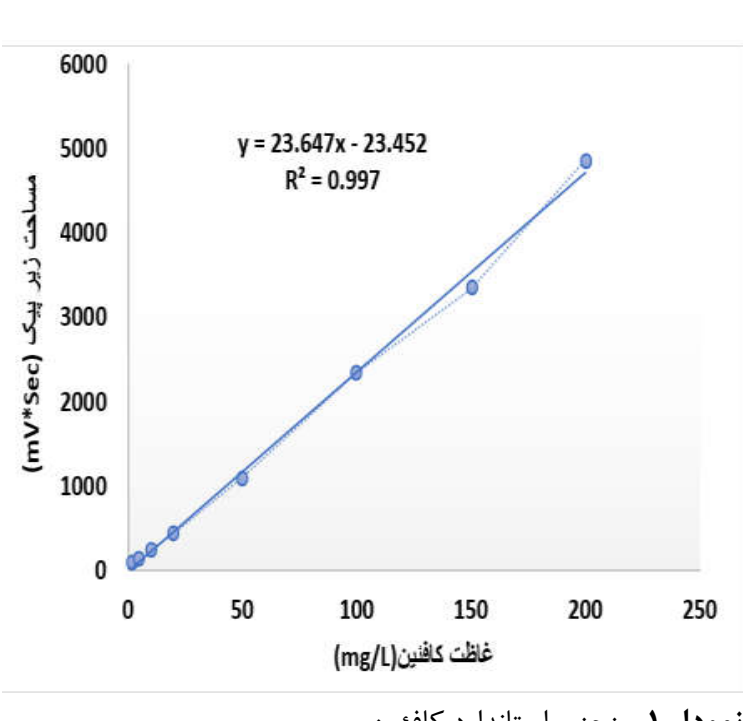

حدود تعيين مقدار و حدود شناسايى: با بررسى انجام شده ميزان LOQ به دست آمده LF/\&D $\mu \mathrm{g} / \mathrm{mL}$ آن 
جدول r. نتايج حاصل از بررسى دقت روش در سه روز كارى

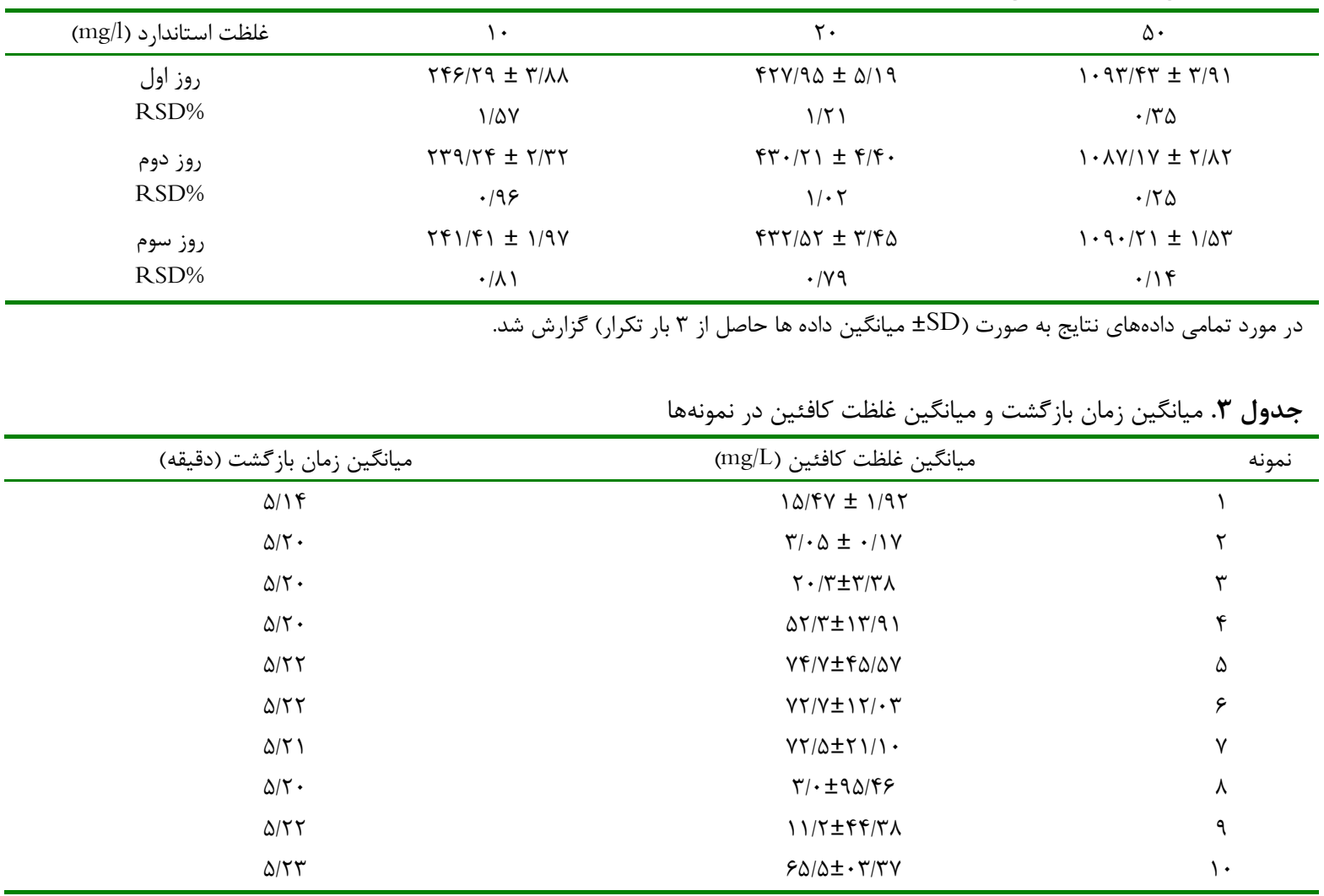

جدول f. ميزان دريافت روزانه قابل قبول EDI (mg/kg/day) ADI و ميزان دريافت روزانه تخمينى EDI/day كافئين در نمونههاى نوشابه

\begin{tabular}{|c|c|c|c|}
\hline & & \multicolumn{2}{|c|}{ و قهوه در بالغين و مقايسه آن با ADI و محاسبه HI } \\
\hline نمونه & ADI & EDI & $\mathrm{HI} \%$ \\
\hline كافئين نوشابه & $\Delta / V$ & .1 .189 & $\cdot|r|$ \\
\hline كافئين قهوه & $\Delta / V$ & $. \cdots \cdot \mid r$ & $\cdot(\cdots r \mid$ \\
\hline
\end{tabular}

است تا از بروز عواقب احتمالى ناشى از سميت با دوز هاى بالا اين ماده جلوكيرى شود.

مطالعات بسيارى جهت اندازمخيرى كافئين در نوشيدنىها

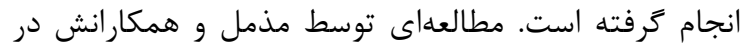

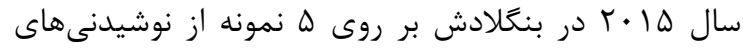

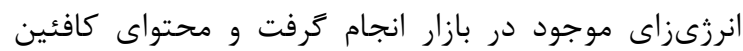

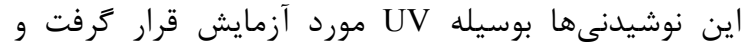

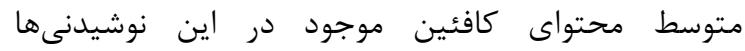

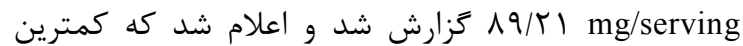
مقدار كافئين در برند شماره f و و بيشترين مقدار كافئين در برند شماره ه است (TQ (T).

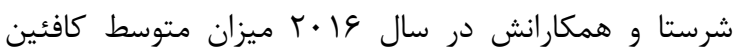

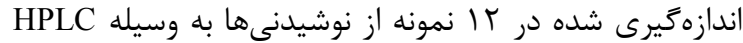
را
اخيراً مصرف نوشيدنىهـاى انرزىزا و حاوى كافئين توسـط

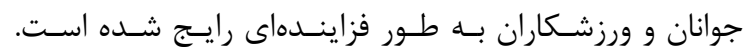

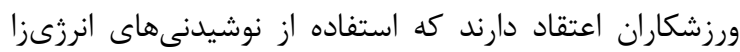

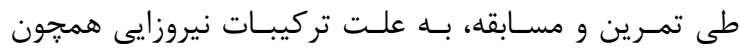

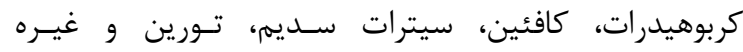

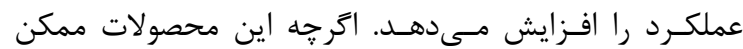
است فوايدى نظير فراهم كردن سريع انرزى، كاهش خستـتى إنى

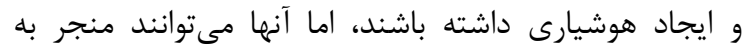
عوارض جدى شوند. اين عوارض در افراد بيمار، به ويرها اشخاص با بيمارىهاى روانى، قلبى و عروقى، سرطان و و كليوى خيلى خطرناكتر هستند.

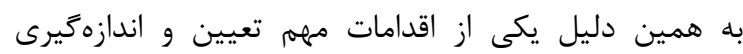
كافئين موجود در اين نوشيدنىها در بازههاى زمانى مختلف 


$$
\begin{aligned}
& \text { قرار بخيرند. در اين يزوهش از HPLC به عنوان روشى سريع، } \\
& \text { آسكى و همكارانش در تركيه در سال } 91 \text { • ب از HPLC براى } \\
& \text { حساس و كارآمد به همراه دتكتور UV استفاده شده است. } \\
& \text { اندازهيرى كافئين نوشيدنىهاى غيرالكلى استفاده كردند و } \\
& \text { در يزوهش حاضر سعى شد يك روش آناليز دقيق و حساس }
\end{aligned}
$$

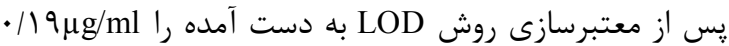

$$
\begin{aligned}
& \text { جهت اندازهخيرى كافئين · ا نمونه از نوشيدنىها اعتبارسنجى } \\
& \text { شود. نتايج به دست آمده نشان مىدهد كه اين روش كاملا } \\
& \text { علمى و عملى است. به طورى كه منحنى كاليبراسيون براى }
\end{aligned}
$$

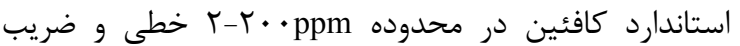

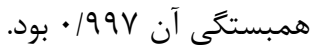

$$
\begin{aligned}
& \text { نتايج حاصل از اندازهخيرى كافئين نمونههاى مورد استفاده دراه بود } \\
& \text { يروهش نشان مىدهد كه كمترين مقدار كافئين مربوط به }
\end{aligned}
$$

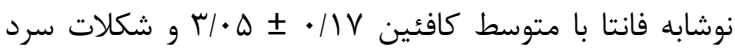

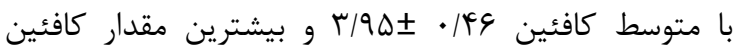

$$
\begin{aligned}
& \text { وربوط به نوشابه ردبول با متوسط كافئين VY/KDE V/OV }
\end{aligned}
$$

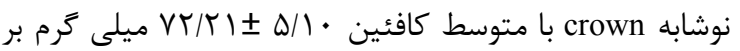

$$
\begin{aligned}
& \text { ليتر است. } \\
& \text { ميزان دريافت روزانه تخمينى (EDI) كافئين با استفاده از }
\end{aligned}
$$

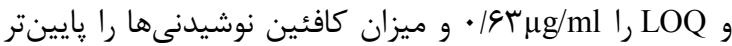

$$
\begin{aligned}
& \text { از حد مجاز اعلام شده گزارش كردند (TV). }
\end{aligned}
$$

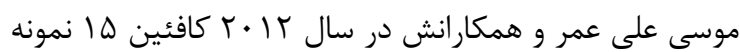

$$
\begin{aligned}
& \text { نوشيدنى موجود در بازار سودان را به وسيله HPLC مورد } \\
& \text { سنجش قرار دادند و متوسط كافئين موجود در نوشابههاى }
\end{aligned}
$$

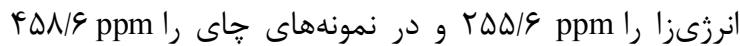

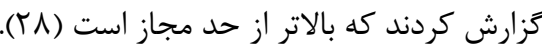

$$
\begin{aligned}
& \text { در سال ؟ ×. r مطالعهاى توسط عبدل مومن و همكارانش } \\
& \text { براى اندازهخيرى كافئين در جاى و قهوه و نوشيدنى ها به روش موري } \\
& \text { SPE-HPLC } \\
& \text { نوشيدنىها در محدوده 1/Dppm • | 19r-1 و محتواى كافئين }
\end{aligned}
$$

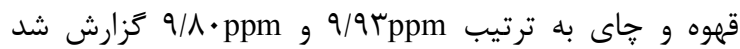

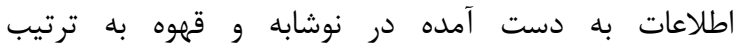

$$
\begin{aligned}
& \text { IV9 mg/kg/day } \\
& \text { ميزان جذب روزانه قابل قبول (ADI) نشان دهنده عدم وجود } \\
& \text { خطر براى مصرف كنندگان اين محصولات است. } \\
& \text { در حال حاضر محققان براى تعيين محتواى كافئين اين }
\end{aligned}
$$

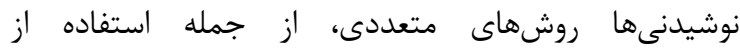

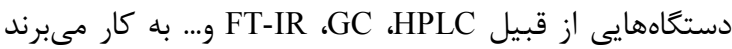

$$
\begin{aligned}
& \text { كه هركدام همراه دتكتورهاى مختلف مىتوانند مورد مطالعه }
\end{aligned}
$$

\section{REFERENCES}

1. McClaran SR, Wetter TJ. Low doses of caffeine reduce heart rate during submaximal cycle ergometry. J Int Soc Sports Nutr 2007; 4:11.

2. Jun X, Caffeine extraction from green tea leaves assisted by high pressure processing. J Food Engin 2009; 94:105109.

3. Svorc LU, Tomcík P, Svitkova J, Rievaj M, Bustin D. Voltammetric determination of caffeine in beverage samples on bare boron-doped diamond electrode. Food Chem 2012; 135:1198-1204.

4. Damirchi A, Rahmani-nia FA, Mirzaei BA, Hasan-Nia S, Ebrahimi MO. Effect of caffeine on blood pressure during exercise and at rest in overweight men. Iran J Endocrin Metabol 2009; 10:623-663.

5. Saadaatian A, Editor. Natural and treating features of fruits and vegetables. Tehran: AyandeSazan Shahr Ab Publication, 2007; 72 .

6. Ribeiro J, Sebastiao AM, Caffeine and adenosine. J Alzheimer's Dis 2010; 20: 3-15.

7. Demirtas C, Ofuoglu E, Hussein A, Pasaoglu H. Effects of caffeine on oxidant-antioxidant mechanism in the rat liver. Gazi Med J 2012; 23:13-8.

8.Mort JR, Kruse HR. Timing of blood pressure measurement related to caffeine consumption. Ann Pharmacother 2008; 42:105-110.

9. Rostagno MA, Manchon N, Darrigo M, Guillamon E, Villares A, Garcia-Lafuente A, et al. Fast and simultaneous determination of phenolic compounds and caffeine in teas, mate, instant coffee, soft drink and energetic drink by highperformance liquid chromatography using a fused-core column. Analytica chimica acta 2011; 685:204-211.

10. Tobolkina E, Qiao L, Roussel C, Girault HH. Standard addition strip for quantitative electrostatic spray ionization mass spectrometry analysis: Determination of caffeine in drinks. Talanta 2014; 130:377-381.

11. Ker K, Edwards PJ, Felix LM, Blackhall K, Roberts I. Caffeine for the prevention of injuries and errors in shift workers. Cochrane Database Syst Rev 2010; 12:5.

12. Einother SJ, Giesbrecht T. Caffeine as an attention enhancer: reviewing existing assumptions. Psychopharmacology 2013; 225: 251-274. 
13. Bloms LP, Fitzgerald JS, Short MW, Whitehead JR. The effects of caffeine on vertical jump height and execution in collegiate athletes. J Strength Cond Res 2016; 30: 1855-1861.

14. Davicino R, Alonso R, and Anesini C, Comparison between normal coffee and decaffeinated coffee effects on lymphocytes and macrophages: role of the antioxidant activity of caffeine. J Food Biochem 2011; 35: 877-897.

15. Hasko $\mathrm{G}$ and Cronstein B. Methylxanthines and inflammatory cells. In: Fredholm BB, Editor. Methylxanthines. Berlin: Springer; 2011. P.457-68.

16. Collomp K, Ahmaidi S, Chatard JC, Audran M, Prefaut C. Benefits of caffeine ingestion on sprint performance in trained and untrained swimmers. Eur J Appl Physiol 1992; 64:377-380

17. Babu KM, Church RJ, Lewander W. Energy drinks: the new eye-opener for adolescents. Clin Pediatr Emer Med 200; 9:35-42.

18. Paydas S, Sonay Y, Avci A, Duman BB, Tumkaya E. Energy drinks and chemotherapy: can these products cause detrimental effects in cancer patients receiving chemotherapy? Eur J Intern Med 2013; 24:3-4.

19. Dikici S, Saritas A, Besir FH, Tasci AH, Kandis H. Do energy drinks cause epileptic seizure and ischemic stroke? Am J Emerg Med 2013; 31:274.

20. Shrivas K, Wu HF. Rapid determination of caffeine in one drop of beverages and foods using drop-to-drop solvent microextraction with gas chromatography/mass spectrometry. J Chromatogr 2007; 1170:9-14.

21. Sinija V, Mishra H. FT-NIR spectroscopy for caffeine estimation in instant green tea powder and granules. LWTFood Sci and Tech 2009; 42:998-1002.

22. Brown J, Kreiger N, Darlington GA. Sloan M, Misclassification of exposure: coffee as a surrogate for caffeine intake. Am J Epidemiol 2001; 153:815-820.

23. Zou J, Li N. Simple and environmental friendly procedure for the gas chromatographic-mass spectrometric determination of caffeine in beverages. J chromate A 2006; 1136:106-110.

24. EFSA Panel on Dietetic Products, Nutritioan and Allergies. Scientific opinion on the safety of caffeine. EFSA Journal 2015; 13:4102.

25. Hossain MM, Jahan I, Shawan MM, Parvin A, Hasan MM, Uddin KR, et al. Determination of $\mathrm{pH}$, caffeine and reducing sugar in energy drinks available in Bangladesh. NY Sci J 2015; 8:92-96.

26. Pokhrel P, Shrestha S, Rijal SK, Rai KP. A simple HPLC Method for the Determination of Caffeine Content in Tea and Coffee. J Food Sci and Tech Nepal 2016; 9:74-78.

27. Aşçı B, Dinç Zor S, Aksu Donmez O. Development and validation of HPLC method for the simultaneous determination of five food additives and caffeine in soft drinks. Int J analytical chem 2016; 2016: 2879406.

28. Ali MM, Eisa M, Taha MI, Zakaria BA, Elbashir AA. Determination of caffeine in some Sudanese beverages by High Performance Liquid Chromatography. Pakistan J Nut 2012; 11:336-342.

29. Mumin A, Akhter KF, Abedin Z, Hossain Z. Determination and characterization of caffeine in tea, coffee and soft drinks by solid phase extraction and high performance liquid chromatography (SPE-HPLC). Malaysian J Chem 2006; 8:045-051. 